\title{
Applicability of Baird's Rule for In-Plane Aromaticity
}

\author{
Yui Masumoto, Naoyuki Toriumi, Taisei Osawa, Atsuya Muranaka, ${ }^{*}$ Eiichi Kayahara, Shigeru \\ Yamago, ${ }^{*}$ Mamoru Fujitsuka, Tetsuro Majima, ${ }^{*}$ Masanobu Uchiyama*
}

\begin{abstract}
The concept of aromaticity is essential for chemists to understand the nature of many chemical substances. "In-plane" aromaticity is a unique type of aromaticity found in some m-conjugated systems consisting of radially oriented $p$-orbitals. Although in-plane aromaticity has been theoretically predicted about 40 years ago, its intrinsic properties are much less well understood than those of conventional Hückel aromatic systems with perpendicularly oriented $p$-orbitals because of lack of available examples of in-plane aromatic molecules. Here we demonstrate, from both theoretical and experimental aspects, that in-plane aromaticity of cycloparaphenylenes is reversed upon excitation to the lowest triplet state. In-plane non-aromatic neutral forms with a $4 \mathrm{~N}$-electron system and in-plane aromatic dications with a $4 \mathrm{~N}+2$-electron system turn out to be aromatic and anti-aromatic, respectively, indicating that Baird's rule holds for the in-plane aromatic system. Armchair carbon nanotube fragments based on the cycloparaphenylene were also found to follow Baird's rule from a magnetic viewpoint.
\end{abstract}

Aromaticity is one of the most fundamental and important concepts in chemistry, providing a rational basis for understanding the unique structure, stability, reactivity, and optical and magnetic properties of various molecular systems. Planar cyclic conjugated molecules with a Hückel system have long been the main subject of studies on aromaticity since the first report in 1931. ${ }^{[1,2]}$ In 1964, a new type of aromaticity in a Möbius topology was proposed and several Möbius aromatic molecules have since been created. ${ }^{[3-7]}$

[a] Dr. Y. Masumoto, Dr. N. Toriumil ${ }^{[+]}$, T. Osawa, Prof. Dr. M. Uchiyama Graduate School of Pharmaceutical Sciences The University of Tokyo

7-3-1 Hongo, Bunkyo-ku, Tokyo 113-0033 (Japan)

E-mail: uchiyama@mol.f.u-tokyo.ac.jp

[b] Dr. A. Muranaka, Prof. Dr. M. Uchiyama RIKEN

2-1 Hirosawa, Wako-shi, Saitama 351-0198 (Japan)

E-mail: atsuya-muranaka@riken.jp

[c] Prof. Dr. M. Uchiyama

Research Initiative for Supra-Materials (RISM)

Shinshu University

Ueda, 386-8567 (Japan)

[d] Dr. E. Kayahara, Prof. Dr. S. Yamago

Institute for Chemical Research

Kyoto University

Uji 611-0011(Japan)

E-mail: yamago@scl.kyoto-u.ac.jp

[e] Prof. Dr. M. Fujitsuka, Prof. Dr. Tetsuro Majima

The Institute of Scientific and Industrial Research (SANKEN) Osaka University

Mihogaoka 8-1, Ibaraki, Osaka 567-0047 (Japan)

E-mail:majima@sanken.osaka-u.ac.jp

[+] Present address: Department of Chemistry

School of Science, Tokyo Institute of Technology

2-12-1 O-okayama, Megro-ku, Tokyo 152-8551 (Japan)

Supporting information for this article is given via a link at the end of the document.
The third type of aromaticity, "in-plane" aromaticity, was theoretically predicted by Schleyer et al. in $1979 .{ }^{[8]} p$-Orbitals in an in-plane system lie parallel to the ring plane, which is in contrast to the Hückel and Möbius systems (Figure 1). In 2015, we demonstrated both experimentally and theoretically that dicationic carbon nano-rings called [ $n$ ]cycloparaphenylene ( $[n]$ CPP, $n=5-10$ ), which can be regarded as a partial structure of fullerenes or carbon nanotubes, have "in-plane" aromaticity with a $4 N+2$-electron system $(N=n-1)$, while neutral $[n]$ CPPs are in-plane non-aromatic with a $4 N$-electron system $(N=n) \cdot{ }^{[9,10]}$ We further predicted theoretically that the dianions of $[n]$ CPPs are also in-plane aromatic with a $4 N+2$-electron system $(N=n)$. Several highly substituted $\mathrm{C}_{60}$ derivatives (18-electron system) ${ }^{[11]}$ and the hexacation of a porphyrin nano-ring (78-electron system $)^{[12]}$ have also been reported as other examples of in-plane aromatic compounds. These in-plane systems follow the Hückel $4 N+2$ rule and have many similarities to Hückel systems in function and properties. However, the similarities may be superficial, and it is of interest to characterize these compounds in detail to determine the origin of the in-plane aromaticity.
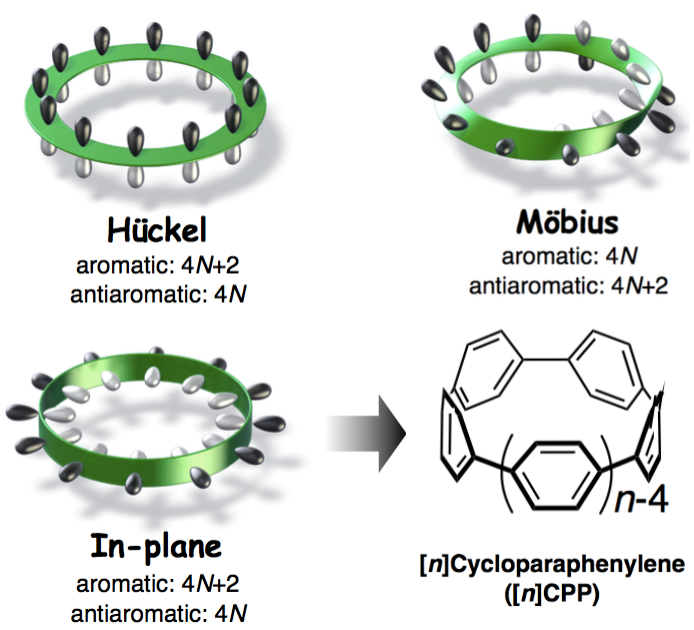

[n]Cycloparaphenylene ([n]CPP)

Figure 1. Schematic illustrations of Hückel aromatic system, Möbius aromatic system, and in-plane aromatic system.

In 1972, Baird proposed that aromaticity and anti-aromaticity of cyclic hydrocarbons are reversed upon excitation from the ground state $\left(\mathrm{S}_{0}\right)$ to the lowest triplet state $\left(\mathrm{T}_{1}\right) \cdot{ }^{[13]} \mathrm{A}$ theoretical study by Schleyer et al. revealed that the magnetic properties of $4 \mathrm{~N} \pi$-electron annulenes such as cyclobutadiene are reversed upon excitation to the $T_{1}$ state. ${ }^{[14]}$ Osuka and Kim et al. proved both theoretically and experimentally that the optical properties of $26 \pi$ - and $28 \pi$-electron hexaphyrins are reversed when these molecules are in the $T_{1}$ state. ${ }^{[15]}$ Aida, Kim, Ottosson, and Itoh et al. succeeded in experimental substantiation of the triplet 
aromaticity in cyclooctatetraene derivatives from an energetic viewpoint. ${ }^{[16]}$ Recently, structural changes of cyclobutadiene derivatives in the $T_{1}$ state were confirmed spectroscopically by Tumanskii, Sekiguchi, and Apeloig et al. ${ }^{[17]}$ But, in contrast to conventional Hückel aromatic systems, Baird's rule for in-plane aromatic compounds has never been experimentally explored. ${ }^{[18,19]}[n]$ CPPs are structurally ideal molecules for systematically and experimentally evaluating in-plane aromatic properties, and various [ $n$ ]CPPs are now commercially available. Herein we report a theoretical and experimental study to determine whether Baird's rule holds for in-plane aromatic [n]CPPs.

We commenced our study by computing the nucleusindependent chemical shift (NICS) values at the center of the nano-ring of [8]CPP and [8]CPP ${ }^{2+}$ between the $S_{0}$ and the $T_{1}$ states at the (U)B3LYP/6-31+G* level (Figure 2a). NICS values have often been used to evaluate the magnetic properties of aromatic compounds ${ }^{[20]}$ and a negative/positive value means that the compound is aromatic/anti-aromatic. We previously reported that the NICS values for [8]CPP $\left(\mathrm{S}_{0}\right)$ and $[8] \mathrm{CPP}^{2+}\left(\mathrm{S}_{0}\right)$ are -2.3 and $-14.0 \mathrm{ppm}^{\left[{ }^{[9]}\right.}$ The NICS value for [8]CPP $\left(\mathrm{T}_{1}\right)$ was strongly negative $(-13.9 \mathrm{ppm})$, indicating in-plane aromaticity from a magnetic point of view. In contrast, the value for $[8] \mathrm{CPP}^{2+}\left(\mathrm{T}_{1}\right)$ was strongly positive $(+12.9 \mathrm{ppm})$, which indicates in-plane antiaromatic character. Similar NICS values were also obtained at the (U)B3LYP/6-311+ $G^{* *}$ or (U)BLYP/6-31+G* level (see Supporting Information).

Two-dimensional NICS plots ${ }^{[21-23]}$ on the plane $3 \AA$ above the center were next calculated to make sure that the aromatic character stems not from each benzene ring, but rather from the whole nano-ring (Figure. $2 \mathrm{~b}$ ). The values on the plane for in-plane non-aromatic [8]CPP $\left(\mathrm{S}_{0}\right)$ were close to zero, whereas the plot for in-plane aromatic $[8] \mathrm{CPP}^{2+}\left(\mathrm{S}_{0}\right)$ showed concentric circles with negative values. ${ }^{\left[{ }^{[0]}\right.}$ The plot for [8]CPP $\left(T_{1}\right)$ was essentially the same as that for $[8] \mathrm{CPP}^{2+}\left(\mathrm{S}_{0}\right)$, which means that diatropic ring current involving the nano-ring exists in [8]CPP $\left(T_{1}\right)$. The NICS plot of [8]CPP ${ }^{2+}$ in the $T_{1}$ state also showed concentrically spread NICS values, but the sign was positive. It can therefore be concluded that Baird's rule holds for the in-plane aromatic [8]CPP ${ }^{2+/ 0}$ system.

We investigated conjugation pathways of the nano-rings by examining the ACID surfaces ${ }^{[24]}$, which are isosurfaces of the anisotropy of the induced current density (Figure 2c). One can see that the blue areas in [8]CPP $\left(\mathrm{T}_{1}\right),[8] \mathrm{CPP}^{2+}\left(\mathrm{S}_{0}\right)$, and [8]CPP ${ }^{2+}$ $\left(\mathrm{T}_{1}\right)$ are rather larger than that in [8]CPP $\left(\mathrm{S}_{0}\right)$, suggesting the existence of macrocyclic conjugation pathways in the former three states. When the isosurface value is plotted at 0.09 , the connection between adjacent benzene rings disappears in [8]CPP $\left(\mathrm{S}_{0}\right)$, which is in sharp contrast to the connected isosurfaces in [8]CPP $\left(\mathrm{T}_{1}\right)$, [8]CPP ${ }^{2+}\left(\mathrm{S}_{0}\right)$, and [8]CPP ${ }^{2+}\left(\mathrm{T}_{1}\right)$ (see Supporting Information).

Optical properties of the nano-rings were compared to further clarify the reversal of in-plane aromaticity. ${ }^{[25-28]}$ Figure 3 shows the experimental and computed absorption spectra of [8]CPP and [8] $\mathrm{CPP}^{2+}$. The steady-state absorption spectrum of [8]CPP shows an intense ultraviolet absorption band and a weak shoulder at the longer wavelength region. ${ }^{[9,29]}$ The weak shoulder can be assigned to the dipole-forbidden $\mathrm{S}_{0} \rightarrow \mathrm{S}_{1}$ transition, which is characteristic of a $4 N \pi$-electron system. In contrast, [8]CPP ${ }^{2+}$ exhibits two intense absorption bands. ${ }^{[9,30]}$ The theoretical absorption spectra obtained from TDDFT calculations reproduced well the experimental spectral patterns (see Supporting Information). The appearance of the calculated $T_{1} \rightarrow T_{n}$ absorption spectrum of [8]CPP is quite similar to that of the calculated $\mathrm{S}_{0} \rightarrow \mathrm{S}_{\mathrm{n}}$ spectrum of $[8] \mathrm{CPP}^{2+}$. The transition absorption spectrum of [8]CPP at 100 ns after laser excitation during laser flash photolysis showed two intense absorption bands. ${ }^{[31]}$ Although the near-infrared band is blue-shifted as compared with the band observed for $[8] \mathrm{CPP}^{2+}\left(\mathrm{S}_{0} \rightarrow \mathrm{S}_{n}\right)$, the molar extinction coefficients of the two bands of [8]CPP $\left(T_{1} \rightarrow T_{n}\right)$ are comparable to those of $[8] \mathrm{CPP}^{2+}\left(\mathrm{S}_{0} \rightarrow \mathrm{S}_{\mathrm{n}}\right)$. Transient absorption spectra of [8] $\mathrm{CPP}^{2+}$ during femtosecond laser flash photolysis exhibited spectral changes characterized by threecomponents with a lifetime of 4 ps, 65 ps, and > 1 ns. The component with the shortest lifetime is attributable to the $S_{1}$ state, while the $65 \mathrm{ps}$ and $>1 \mathrm{~ns}$ components are assigned to the hot $\mathrm{S}_{0}$ and $T_{1}$ states, respectively. On the basis of the triplet yield and $\triangle$ Abs. attributable to $T_{1}$ of $[8] \mathrm{CPP}^{2+}$, the extinction coefficient of $\mathrm{T}_{1}$ at around $900 \mathrm{~nm}$ is smaller than that of $S_{1}$ by a factor of $>5$. The substantially weak and blue-shifted absorption bands of the $T_{1}$ state agreed with the theoretical calculation results, supporting the anti-aromatic character.

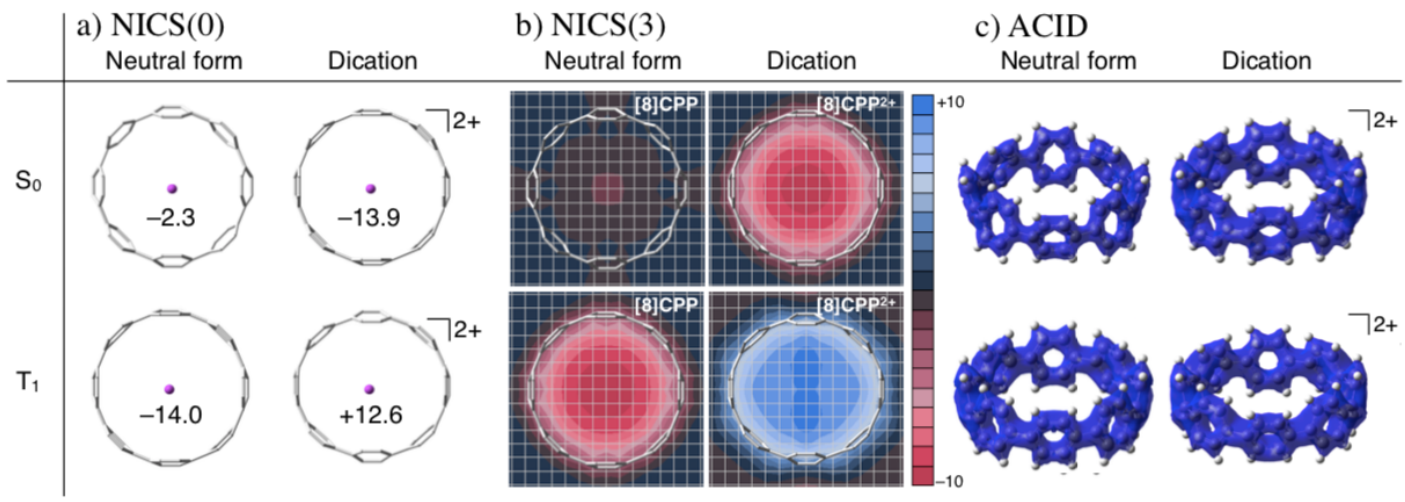

Figure 2. a) Optimized structures and NICS values (in ppm) of [8]CPP and [8]CPP ${ }^{2+}$, b) two-dimensional NICS plots, and c) ACID plots (isosurface value $=0.05$ ) Hydrogen atoms were omitted for $a$ ) and b). All calculations were performed at (U)B3LYP/6-31+G* level. 

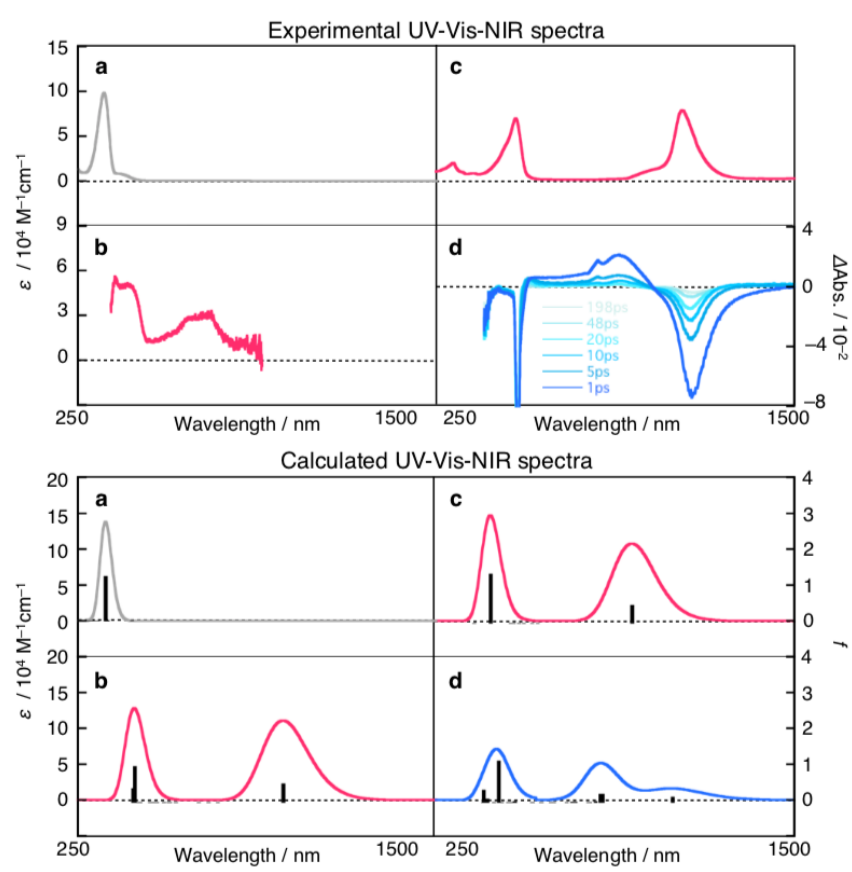

Figure 3. Experimental (top) and computed (bottom) absorptionspectra of a, [8]CPP $\left(\mathrm{S}_{0} \rightarrow \mathrm{S}_{\mathrm{n}}\right), \mathrm{b}$, [8]CPP $\left(\mathrm{T}_{1} \rightarrow \mathrm{T}_{\mathrm{n}}\right), \mathrm{c},[8] \mathrm{CPP}^{2+}\left(\mathrm{S}_{0} \rightarrow \mathrm{S}_{\mathrm{n}}\right)$, and d, [8]CPP ${ }^{2+}$ $\left(\mathrm{T}_{1} \rightarrow \mathrm{T}_{\mathrm{n}}\right)$ measured in $\mathrm{CH}_{2} \mathrm{Cl}_{2}{ }^{\left[{ }^{9}\right]}$ All calculations were performed at the (U)B3LYP/6-31+G* level. Gaussian bands with a half-bandwidth of $2000 \mathrm{~cm}^{-1}$ (250-600 nm region) or $1000 \mathrm{~cm}^{-1}(601-1500 \mathrm{~nm}$ region) were used to produce the calculated spectra.

In order to gain insight into the generality of the reversal of inplane aromaticity, NICS values of $[n] \mathrm{CPP}^{2+/ 0 / 2-}(n=5-10)$ were calculated. Quite recently, Jasti and Petrukhina et al. synthesized and characterized the dianion of [6]CPP, but no clear evidences for the presence of in-plane aromaticity was provided besides the bond alternation. ${ }^{[32]}$ The electronic structure of the dianion $\left([6] \mathrm{CPP}^{2-}\right)$ can be regarded as a 30 -electron system. The NICS value of [6]CPP ${ }^{2-}$ was calculated to be strongly negative $(-16.5$ $\mathrm{ppm})$ in the $\mathrm{S}_{0}$ state, but became strongly positive $(+15.1 \mathrm{ppm})$ in the $T_{1}$ state. Reversal of the NICS values were also calculated for $[n] \mathrm{CPP}^{2+/ 2-} \mathrm{S}$ (see Supporting Information). The positive values of NICS for $[n] \mathrm{CPP}^{2+}\left(\mathrm{T}_{1}\right)$ and $[n] \mathrm{CPP}^{2-}\left(\mathrm{T}_{1}\right)$ increased with decreasing size of the nano-rings. In the case of the neutral forms ([n]CPP), the NICS value was found to be very sensitive to slight geometrical changes. The NICS values for the optimized structure of [7]CPP $\left(T_{1}\right)$ and [9]CPP $\left(T_{1}\right)$ were not strongly negative. When we calculated the NICS value using [7]CPP $\left(\mathrm{T}_{1}\right)$ with $D_{7 h}$ symmetry or [9]CPP $\left(T_{1}\right)$ with $D_{9 h}$ symmetry, strongly negative values were obtained (see Supporting Information).

Interestingly, not only CPPs but also m-extended carbon nanotube fragments follow Baird's rule, at least from a magnetic viewpoint. We calculated NICS values for armchair carbon nanobelts based on [6]CPP. ${ }^{[33]}$ Strongly negative NICS values were calculated inside the tube for the $T_{1}$ state of all the nano-belts (Figure 4).

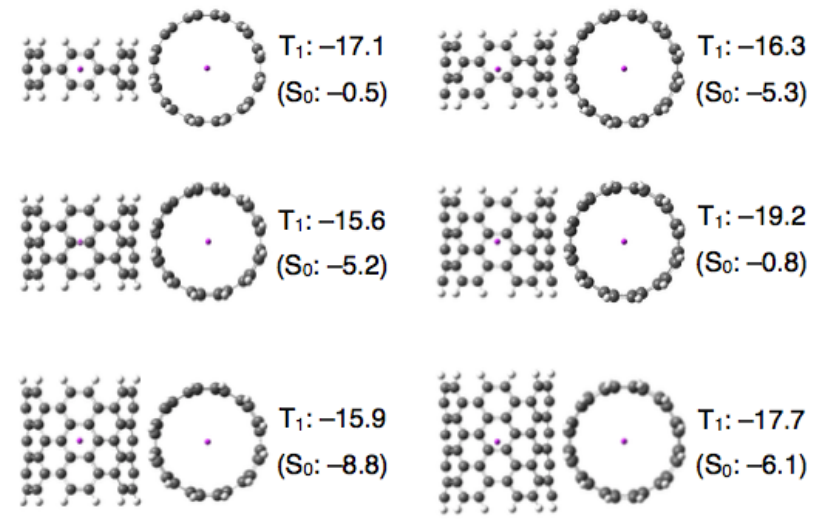

Figure 4. Optimized structures of carbon nano-belts based on [6]CPP in the $\mathrm{T}_{1}$ state and the NICS values (in ppm) at the center of the nano-belt. Each position is shown with a purple ball. The values in the $S_{0}$ state are shown in parentheses. All calculations were performed at the (U)B3LYP/6-31G* level.

In conclusion, we computed the magnetic properties of the $T_{1}$ state of various $[n]$ CPP systems. The nano-rings with $4 N \pi /(4 N+2) \pi$-electrons were magnetically in-plane aromatic/antiaromatic. Spectroscopic studies of [8]CPP ${ }^{2+10}$ revealed reversal of optical properties between the $S_{0}$ and $T_{1}$ states. These results lead to the conclusion that Baird's rule holds for in-plane aromaticity in $[n]$ CPP systems.

\section{Acknowledgements}

This work was partly supported by JSPS KAKENHI ((S) No.17H06173 to M.U.), ((S) No.16H06352 to S.Y.), and ((C) No.26410043 to E.K.). It was also supported by The Asahi Glass Foundation, Foundation NAGASE Science Technology Development, Sumitomo Foundation, (to M.U.), Collaborative Research Program of Institute for Chemical Research, Kyoto University (to M.U. and A.M.), and RIKEN Junior Research Associate Program (to Y.M.). HOKUSAI GreatWave and BigWaterfall (RIKEN) provided the computer resources for the DFT calculations.

Keywords: aromaticity $\cdot$ magnetic properties $\cdot$ hydrocarbons• absorption

[1] E. Hückel, Z. Phys. 1931, 72, 310-337.

[2] P. v. R. Schleyer, H. Jiao, Pure Appl. Chem. 1996, 68, 209-218.

[3] E. Heilbronner, Tetrahedron Lett. 1964, 5, 1923-1928.

[4] D. Ajami, O. Oeckler, A. Simon, R. Herges, Nature 2003, 426, 819-821.

[5] M. Stepien, M. L. Grazynski, N. Sprutta, P. Chwalisz, L. Szterenberg, Angew. Chem. Int. Ed. 2007, 46, 7869-7873.

[6] Z. S. Yoon, A. Osuka, D. Kim, Nat. Chem. 2009, 1, 113-122.

[7] M. Izawa, T. Kim, S. Ishida, T. Tanaka, T. Mori, D. Kim, A. Osuka, Angew. Chem. Int. Ed. 2017, 56, 3982-3986.

[8] J. Chandrasekhar, E. D. Jemmis, P. v. R. Schleyer, Tetrahedron Lett. 1979, 20, 3707-3710.

[9] N. Toriumi, A. Muranaka, E. Kayahara, S. Yamago, M. Uchiyama, J. Am. Chem. Soc. 2015, 137, 82-85.

[10] E. Kayahara, T. Kouyama, T. Kato, S. Yamago, J. Am. Chem. Soc. 2016, $138,338-344$. 
[11] G. A. Burley, Angew. Chem. Int. Ed. 2005, 44, 3176-3178.

[12] M. D. Peeks, T. D. W. Claridge, H. L. Anderson, Nature 2016, 541, $200-$ 203

[13] N. C. Baird, J. Am. Chem. Soc. 1972, 94, 4941-4948.

[14] V. Gogonea, P. v. R. Schleyer, P. R. Schreiner, Angew. Chem. Int. Ed. 1998, 37, 1945-1948.

[15] Y. M. Sung, M.-C. Yoon, J. M. Lim, H. Rath, K. Naoda, A. Osuka, D. Kim, Nat. Chem. 2015, 7, 418-422.

[16] M. Ueda, K. Jorner, Y. M. Sung, T. Mori, Q. Xiao, D. Kim, H. Ottosson, T. Aida, Y. Ito, Nat. Commun. 2017, 8, 346.

[17] A. Kostenko, B. Tumanskii, Y. Kobayashi, M. Nakamoto, A. Sekiguchi, Y. Apeloig, Angew. Chem. Int. Ed. 2017, 56,10183-10187.

[18] A. A. Fokin, H. Jiao, P. v. R. Schleyer, J. Am. Chem. Soc. 1998, 120, 9364-9365.

[19] M. D. Peeks, J. Q. Gong, K. McLoughlin, T. Kobataje, R. Haver, L. M. Herz, H. L. Anderson, J. Phys. Chem. Lett. 2019, 10, 2107-2022.

[20] P. v. R. Schleyer, C. Meaerker, A. Dransfeld, H. Jiao, N. J. R. v. E. Hommes, J. Am. Chem. Soc. 1996, 118, 6317-6318.

[21] S. Kold, E. Kleinpeter, J. Chem. Soc., Perkin Trans. 2 2001, 1893-1898.

[22] E., Kleinpeter, S. Kold, A. Koch, J. Mol. Struct. 2007, 811, 45-60.

[23] D. Sebastiani, K. N. Kudin, ACS Nano 2008, 2, 661-668.

[24] R. Herges, D. Geuenich, J. Phys. Chem. A 2001, 105, 3214-3220.
[25] T. Nishihara, Y. Segawa, K. Itami, Y. Kanemitsu, J. Phys. Chem. Lett. 2012, 3, 3125-3128.

[26] T. Iwamoto, Y. Watanabe, Y., Sakamoto, T. Suzuki, S. Yamago, J. Am Chem. Soc. 2011, 133, 8354-8361.

[27] D. A. Hines, E. R. Darzi, R. Jasti, P. V. Kamat, J. Phys. Chem. A 2014, $118,1595-1600$.

[28] M. Fujituka, S. Tojo, T. Iwamoto, E. Kayahara, S. Yamago, T. Majima, J. Phys. Chem. Lett. 2014, 5, 2302-2305.

[29] S. Yamago, Y. Watanabe, T. Iwamoto, Angew. Chem. Int. Ed. 2010, 49, 757-759.

[30] E. Kayahara, T. Kouyama, T. Kato, H. Takaya, N. Yasuda, S. Yamago, Angew. Chem., Int. Ed. 2013, 52, 13722-13726.

[31] M. Fujitsuka, C. Lu, T. Iwamoto, E. Kayahara, S. Yamago, T. Majima, J. Phys. Chem. A 2014, 118, 4527-4532.

[32] S. N. Spisak, Z. Wei, E. Darzi, R. Jasti, M. A. Petrukhina, Chem. Commun. 2018, 54, 7818-7821.

[33] G. Povie, Y. Segawa, T. Nishihara, Y. Miyauchi, K. Itami, Science 2017, 356, 172-175. 